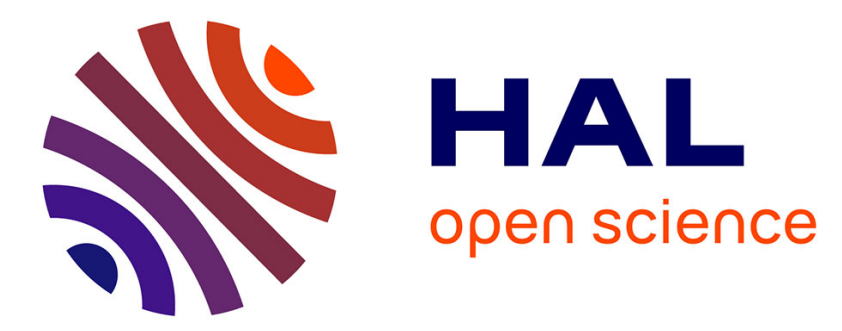

\title{
Edge illuminated SiGe heterojunction phototransistor for RoF applications
}

Z G Tegegne, C Viana, J L Polleux, M G Grzeskowiak, Elodie Richalot

\section{To cite this version:}

Z G Tegegne, C Viana, J L Polleux, M G Grzeskowiak, Elodie Richalot. Edge illuminated SiGe heterojunction phototransistor for RoF applications. Electronics Letters, 2015, 51, pp.1906 - 1908. 10.1049/el.2015.2448. hal-01436923

\section{HAL Id: hal-01436923 https://hal.science/hal-01436923}

Submitted on 16 Jan 2017

HAL is a multi-disciplinary open access archive for the deposit and dissemination of scientific research documents, whether they are published or not. The documents may come from teaching and research institutions in France or abroad, or from public or private research centers.
L'archive ouverte pluridisciplinaire HAL, est destinée au dépôt et à la diffusion de documents scientifiques de niveau recherche, publiés ou non, émanant des établissements d'enseignement et de recherche français ou étrangers, des laboratoires publics ou privés. 


\section{Edge illuminated SiGe Heterojunction Phototransistor for RoF applications}

\section{Z.G. Tegegne, C. Viana, J.L. Polleux, M. Grzeskowiak and E.Richalot}

The first edge illuminated SiGe phototransistor based on the available commercial SiGe/Si BiCMOS technology for low cost detector or mixer in Radio-over-Fiber applications. Its technology and structure are described. Edge mapping of the phototransistor performances, so as to observe the fastest and the highest sensitive areas of the structure, is performed. The phototransistor exhibits a cutoff frequency of $890 \mathrm{MHz}$ and low frequency responsivity of $0.45 \mathrm{~A} / \mathrm{W}$ at $850 \mathrm{~nm}$. This new $\mathrm{SiGe} / \mathrm{Si}$ phototransistor structure provides a cutoff frequency double to the one of a top illuminated $\mathrm{SiGe} / \mathrm{Si}$ phototransistor obtained using the same BiCMOS technology.

Introduction: The use of optics for short distance communications have been recognized as an alternative media of transmitting signals for high data applications. Thus, silicon based optoelectronic transceivers and Vertical Cavity Surface Emitting Lasers (VCSELs) are of great interest owing to their low cost, compactness and reliability. In particular, because of the recent demand for $60 \mathrm{GHz}$ Radio-over-Fiber (RoF) applications [1], low cost silicon based optoelectronics are highly desirable in this frequency band. SiGe Heterojunction Bipolar Phototransistors (HPTs) are promising devices for light detection and mixer applications in microwave photonic systems. Several laboratories have developed SiGe HPTs using different industrial technological processes like Atmel [2], TSMC [3], IBM [4] and AMS [5]. All these approaches have led to vertical illuminated structures. Vertically illuminated HPTs or photodiodes suffer from a trade-off between conversion efficiency and frequency performance [6]. Edge coupled HPTs based on InP-InGaAs technology has been intensively studied since 1993 [6] that overcomes this tradeoff.

This paper demonstrates the first edge illuminated SiGe HPTs fabricated using the $80 \mathrm{GHz}$ SiGe2RF Telefunken GmbH SiGe Bipolar technological process. Its performance in terms of cutoff frequency and opto-microwave gain are presented. Due to the use of an industrial technological process, this phototransistor can be implemented to realise a complete optical receiver of $3 \mathrm{Gbp} / \mathrm{s}$ data transmission [7].

SiGe/Si edge illuminated HPT Structure: The SiGe/Si HPT structure was implemented using the existing industrial SiGe2RF Telefunken $\mathrm{GmbH}$ technology. This technology permits obtaining a HPT with an electrical $f_{T}$ of up to $80 \mathrm{GHz}$ and $f_{\max }$ of up to $90 \mathrm{GHz}$. The general scheme of the HBT cross-section is shown in Fig. 1. Indeed, the phototransistor fabrication does not modify the vertical stacks of layers that are used to define a standard technology SiGe2RF HBT. This ensures the compatibility with the process technology and the potential integration of complete OE-RF circuits.

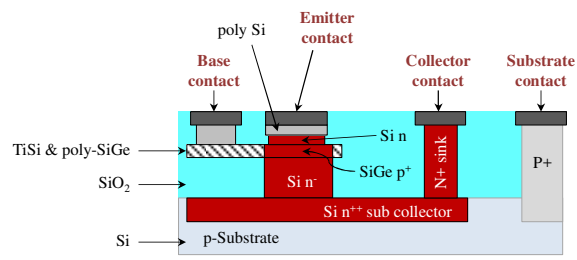

Fig. 1: Schematic cross-section of SiGe2RF technology from Telefunken

The basic HPT structure is designed by extending the emitter, base and collector layers of the reference HBT to increase the size of the HPT from $0.8 \times 1.4 \mu \mathrm{m}^{2}$ to $4.5 \times 5 \mu \mathrm{m}^{2}$ for better coupling with the optical fiber as shown in Fig. 2b. The emitter metal contact is deposited on a reduced surface to avoid additional optical losses and to reduce the electrical parasitic capacitances. The optical access at the edge is obtained after the standard fabrication process through polishing and dicing close to the active area of the devices as shown in Fig. 2a. We polish $80 \mu \mathrm{m}$ down to the substrate to have smooth surface at the optical beam input and then dice using a microscopic saw.

We have designed a $4.5 \mu \mathrm{m}$ thick (where light is coupled through) and $5 \mu \mathrm{m}$ long (maximum absorption length) phototransistor as shown in
Fig. 2b. The $\mathrm{Si}_{1-\mathrm{x}} \mathrm{G}_{\mathrm{e}}$ base layer sandwiched between the collector and emitter, both made of Silicon, is used as an evanescent optical waveguide that detects light. The base profile is a 40-80nm thin abrupt SiGe layer with Ge content in the range of $20-25 \%$ and high $\mathrm{p}$ doping in the range of $10^{19} \mathrm{~cm}^{-3}$. The collector is typically $300-400 \mathrm{~nm}$ thick with low doping.
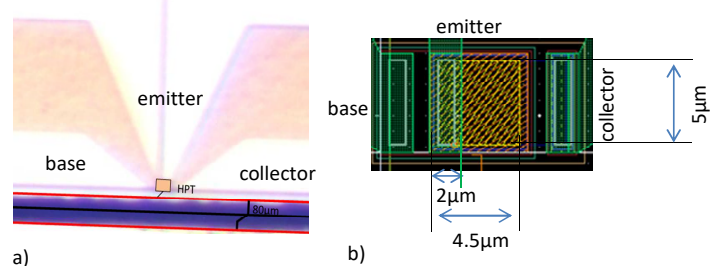

Fig. 2: a) The microscopic picture of the edge illuminated HPT, b) The layout of the edge illuminated HPT along with its dimensions.

Opto-Microwave Characterization: The on-wafer bench setup described in [8] was modified and used to measure the opto-microwave performances of edge side illuminated HPT. Where an 850nm VCSEL, which is directly modulate and illuminate the HPT through a lensed multimode fiber (MMF) scanning the edge of the HPT. This VCSEL has a $-3 \mathrm{~dB}$ cutoff frequency of $12 \mathrm{GHz}$ [9]. The VCSEL is biased so as to provide a $1.14 \mathrm{~mW}$ optical beam at the end of the lensed fiber. A tilted mirror is used to monitor the alignment of the optical probe to the optical window of the HPT on the edge through the microscope as shown in Fig. 3. This distance is set at $50 \mu \mathrm{m}$ from the surface to align the optical window with the beam waist. We use a multimode light source and multimode optical probe to characterise our device as it is targeted to implement in Home Area Network (HAN) applications where multimode sources and MMF are largely deployed at 850nm [1].

The optical probe was scanned all over the HPT's optical window surface on the edge side. For each position, S-parameters of the optical link are measured in the $[50 \mathrm{MHz}-20 \mathrm{GHz}]$ frequency range using the VNA. A $2 \mu \mathrm{m}$ step $(+/-20 \mathrm{~nm})$ was used to cover a $60 \mu \mathrm{mx} 60 \mu \mathrm{m}$ surface over the edge of the HPT. A complete Opto-Microwave Scanning Nearfield Optical Microscopy (OM-SNOM) view of the HPT under test was then taken.

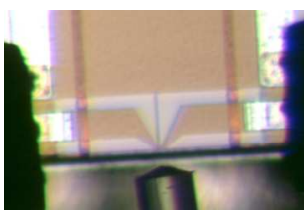

a)

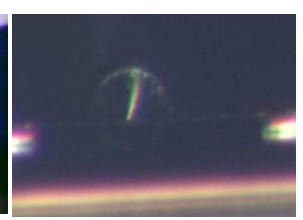

b)
Fig. 3: a) Top view of the the HPT and its interconnection accesses; $b$ ) Front view through the tilted mirror of the fiber probe spot.

The HPT is mounted in a common emitter configuration topology with two $100 \mu \mathrm{m}$-pitch GSG pads in order to perform on wafer microwave measurements as shown in Fig. 3a. One of the ground panels of the HPT was removed during dicing so that one of the GSG ground line was suspended on air.

A proper de-embedding technique was required to extract the behavior of the HPT from the pads, interconnections, optical links and probes. We used T-matrix approach [8] to remove all the parasitics from the measurement bench setup.

Before performing OM-SNOM investigation to look for the fastest and highest sensitive areas of the HPT, we optimised the dc biasing conditions of the phototransistor with respect to the low frequency responsivity and the cutoff frequency at a fixed optical probe position. We found the optimum biasing conditions to maximise both parameters are $0.85 \mathrm{~V}$ at the base-emitter junction and $1.5 \mathrm{~V}$ at the collector-emitter junction. We use this dc biasing conditions for further experimental studies.

Fig. 4 shows the edge map of the normalized responsivity at $50 \mathrm{MHz}$. The optical beam that was scanned over the HPT is assumed to have a Gaussian profile along $x$ - and $z$-axes. The line at $z=0 \mu m$ shows the middle of the active area, for $z>0 \mu m$ the optical fiber goes down to the 
substrate and for $z<0 \mu m$ it moves to the air. The base and collector contacts are at the positive and negative sides of $x$-axis respectively.

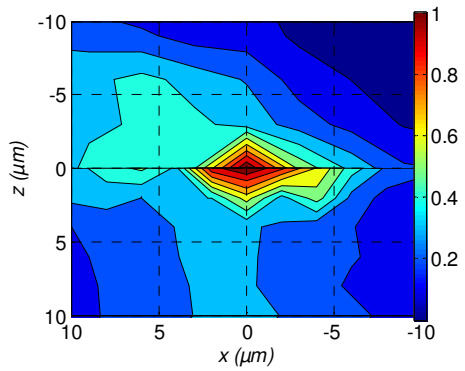

Fig. 4: The edge map of normalized responsivity at $50 \mathrm{MHz}$.

The peak of the responsivity appears at $x=z=0 \mu m$. Fig. 5 compares the opto-microwave gain (Gom) against frequency for an edge illuminated HPT at $x=z=0 \mu m$ (where the peak of responsivity appears) and $x=-4 \mu m, z=0 \mu m$ (where the peak of $\mathrm{f}_{-3 \mathrm{~dB}}$ appears) with a top illuminated HPT having a 10x10 $\mu \mathrm{m}^{2}$ optical window (and obtained using the same technological process). For a top illuminated SiGe HPT, a $10 \mathrm{x} 10 \mu \mathrm{m}^{2}$ optical window size leads to the best performances in terms of opto-microwave responsivity and cutoff frequency compared to other optical window sizes [10]. As shown in Fig. 5, we observed a low frequency $(50 \mathrm{MHz})$ opto-microwave gain of $-7 \mathrm{~dB}$ (opto-microwave responsivity of $0.45 \mathrm{~A} / \mathrm{W}$ ) and $-10 \mathrm{~dB}$ (opto-microwave responsivity of $0.32 \mathrm{~A} / \mathrm{W}$ ) for edge and top side illuminated HPTs respectively. The improvement in the responsivity for edge side illumination is related to the increase of the absorption length. It can be up to $5 \mu \mathrm{m}$ long whereas for top illuminated HPT the absorption length is less than $1 \mu \mathrm{m}$ (which is the total thickness of the active area including emitter, base and collector).

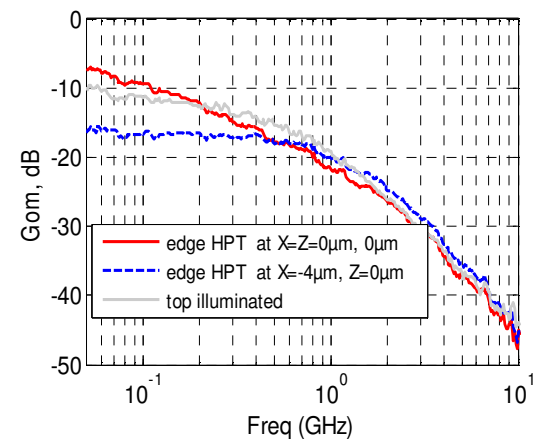

Fig. 5: The Gom as a function of frequency of edge and top illuminated HPT.

The dynamic behavior of the phototransistor over the illumination surface of the structure was analysed through the cutoff frequency $f_{-3 d B}$ in phototransistor mode. The peak of the $f_{-3 d B}$ is located at $x=-4 \mu \mathrm{m}$ and $z=0 \mu \mathrm{m}$. We observed that the edge illuminated HPT can reach up to $890 \mathrm{MHz}$ cutoff frequency whereas the top illuminated one is limited to $420 \mathrm{MHz}$. From this experimental study one can understand that the peaks of the responsivity and $\mathrm{f}-3 \mathrm{~dB}$ could appear at different locations of the structure.

Conclusion: The first edge illuminated SiGe/Si HPT was designed and fabricated by using the existing SiGe BiCMOS technology. A two-step post fabrication process was used to create an optical access on the edge through polishing and dicing techniques. A low frequency optomicrowave responsivity of $0.45 \mathrm{~A} / \mathrm{W}$ and opto-microwave cutoff frequency of $890 \mathrm{MHz}$ was measured. Compared to top illuminated HPT, edge illuminated HPT improves the cutoff frequency by more than a factor two and also improves the responsivity from $0.32 \mathrm{~A} / \mathrm{W}$ to $0.45 \mathrm{~A} / \mathrm{W}$ while using a simple lensed MMF fiber for the coupling. This phototransistor could be used in further opto-microwave applications whose operating frequency could lie in the $1-10 \mathrm{GHz}$ range where integration to Si Integrated Circuits (ICs) and costs are the main issues. Further optical coupling structures could improve the performances. However, these results demonstrate that a simple etched HPT is sufficient to achieve improvements compared to the top illuminated HPT without the need of complex coupling structure, even when using MMF.

Acknowledgments: This work was carried out in the frame of the French FUI8 ORIGIN project. The dicing and polishing processes of the devices were performed at the nano-center CTU-IEF-Minerve, which is partially funded by the "Conseil Général de l'Essonne". This work was partly supported by the French RENATECH network. Authors also thank David Bouville and Laurent Vivien from CNRS and University of Paris-Sud for their technical helps.

Z.G. Tegegne, C. Viana, J.L. Polleux, M. Grzeskowiak, E.Richalot (Université Paris-EST, ESYCOM (EA2552), ESIEE-Paris - UPEM - Le Cnam, 93162 Noisy_le_Grand)

E-mail:tegegnez@esiee.fr

\section{References}

1. J. Guillory et al., "60GHz Intermediate Frequency over Fiber using a passive Multipoint-to-Multipoint architecture", in the $16^{\text {th }}$ European conference on Networks and Optical Communications, NOC, July 2011.

2. J.L. Polleux et al "A Strained SiGe layer Heterojunction Bipolar Phototransistor for Short-Range Opto-Microwave Applications," in IEEE International Topical Meeting on Microwave Photonics, MWP2003, Hungary, September 2003.

3. Z. Pei et al., "Bandwidth Enhancement in an Integratable SiGe Phototransistor by Removal of Excess Carriers", in IEEE Electron Device Letters, Vol. 25, N5, pp286-288, May 2004.

4. T. Yin et al., "Low-cost, high efficiency and high-speed SiGe phototransistors in commercial BiCMOS", in IEEE Photonics Technol. Lett., 18 (1) (2006).

5. M.Egels et al. "Design of an optically frequency or phasecontrolled oscillator for hybrid fiber-radio LAN at $5.2 \mathrm{GHz}$,", in Microwave Opt. Technol. Lett., 45 (2), pp. 104-107, 2005.

6. Wake, D et al 'Optically biased, edge coupled InP/InGaAs heterojunction phototransistor', Electron. Lett., 1993, 29, pp. 2217-2219.

7. C. Viana, et al "Hybrid photo-receiver based on SiGe heterojunction photo-transistor for low-cost $60 \mathrm{GHz}$ intermediate-frequency radio-over-fibre applications" IEEE electronic letters, 2015.

8. J. Schiellein et al "Analysis of opto-microwave paths into a InP/InGaAs UTC-HPT," in Microwave Conference (EuMC), 2011 41st European, pp. 949 -952, oct. 2011

9. C. Viana et al, "VCSEL characterizations at the circuit- and system-levels for low-cost RoF applications" in IEEE MMS, 2013

10. M.D.Rosales "Study of SiGe HPT for Radio-over-Fiber Applications", Ph.D. thesis, Université Paris-Est, ESYCOM, ESIEE Paris, UPEM, Le Cnam, June 2014. 